\title{
Use of a simple body-monitoring system in a pilot study on workers exposed to unsealed gamma-ray emitting material
}

\author{
T SUMERLING
}

From the National Radiological Protection Board, Harwell, Didcot, Oxfordshire, UK

\begin{abstract}
A portable body-monitoring system developed by the board uses two detectors, one for whole-body measurements and one for thyroid measurements. It can detect most commonly used gamma-ray emitting nuclides down to levels below those of interest for radiological protection purposes. The system has been used at 11 establishments including hospitals, universities, and research laboratories. Measurements have been made on 109 workers exposed to unsealed gamma-ray emitting material. Some activity other than that due to naturally occurring ${ }^{40}$ potassium was detected in a substantial proportion $(30 \%)$ of those measured. The contaminating nuclides most often detected were ${ }^{125}$ iodine and ${ }^{99} \mathrm{~m}$ technetium. Some cases of contamination with ${ }^{131}$ iodine, ${ }^{137}$ caesium, ${ }^{67}$ gallium, and ${ }^{85}$ strontium were also detected. In most cases the level of activity detected was very low, but in three it was above the derived investigation level for routine monitoring of the nuclide concerned. The need for monitoring and possible monitoring programmes in which such a system would be useful are discussed.
\end{abstract}

Monitoring of workers exposed to gamma-ray emitters for internal contamination has several benefits. In most cases the results of monitoring can be used to reassure workers that no significant internal contamination has occurred. Where low levels of activity are detected, it may be possible to identify operating practices on which attention should be focused-for example, if all workers performing a particular procedure show some contamination. Finally, monitoring can detect those exceptional cases in which by accident or because of unrecognised difficulties a significant intake has occurred.

Personal monitoring for internal contamination may be performed by bioassay or by body monitoring. Only bioassay techniques can be used to detect pure alpha or beta emitters, but most commonly used gamma-ray emitting radionuclides are detectable at radiologically significant levels with simple monitoring equipment. ${ }^{1}$ Body monitoring is a more direct method of assessing internal contamination. The retained activity is measured, not the excreted activity as in bioassay. Therefore, less reliance need be placed on metabolic models,

Received 19 June 1979

Accepted 4 September 1979 although some assumptions about metabolism must be made if calculations of committed dose equivalent or initial intake are required. For intakes of insoluble material, the results of bioassay are particularly difficult to interpret. Problems may arise in interpreting the results of body measurements when the distribution of activity is unknown or when skin or clothing contamination is present. This will only be significant, however, when a high positive result is obtained, and in that case further investigation is possible. An important consideration is that a measurement of body radioactivity is often more acceptable to a worker than the provision of urine or faecal samples. In addition, the reassurance that may be provided to the worker is more immediate.

\section{Equipment and measurements}

The equipment described here is simple and of a type used by several investigators. ${ }^{2-4}$ It is readily transportable and can quickly be made ready for operation at the place of measurement.

With this equipment one cannot detect gamma-ray emitters that are also alpha emitters (radium and thorium, for example) at the low levels that are required for radiological protection purposes. It can be used to detect most gamma-ray emitting 


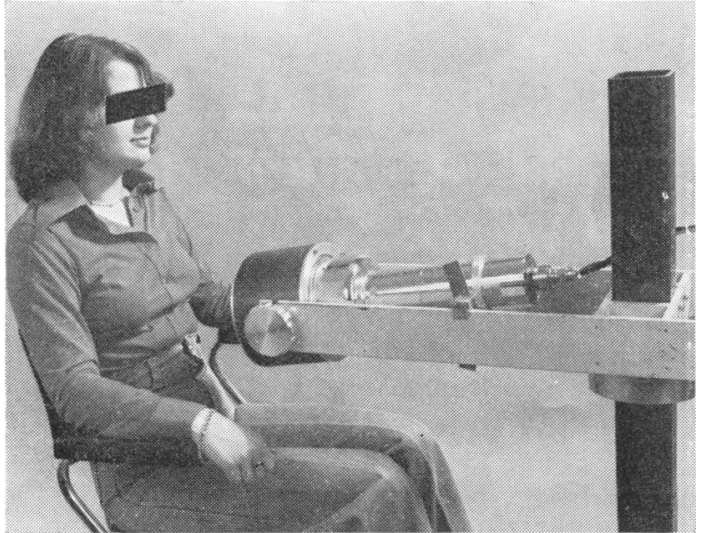

Fig 1 Large NaI detector being used to measure activity distributed in whole body or concentrated in chest (position 1).

nuclides used in medicine and research down to levels well below those considered radiologically significant.

The system employs two detectors. A $13 \mathrm{~cm}$ diameter $\times 10 \mathrm{~cm}$ cylindrical sodium iodide detector with lateral lead shield is used for whole-body measurements, and a $5 \mathrm{~cm}$ diameter $\times 5 \mathrm{~cm}$ sodium iodide detector with lead collimator for thyroid measurements. No other external shielding is used. The gamma-ray spectrum from either detector is accumulated in a multichannel analyser and stored on paper tape.

Whole-body measurements are performed with the subject seated in an office chair (fig 1). The detector efficiency has been determined for various nuclides and for different distributions of activity using phantoms filled with solutions of radionuclides and point sources in a tissue-equivalent phantom. Calibration measurements have been made for two geometries. In position 1 the chair is placed with its back $40 \mathrm{~cm}$ from the detector face, so that the detector views only the trunk region. In position 2 the back of the chair is placed about $65 \mathrm{~cm}$ from the detector face, and the height and angle of the

Table $195 \%$ detection activities for whole body measurements at position 1 for a 500-second count, assuming activity evenly distributed in whole body

\begin{tabular}{lr}
\hline Nuclide & $95 \%$ detection activity $\mathrm{Bq}(\mu \mathrm{Ci})$ \\
\hline${ }^{51} \mathrm{Cr}$ & $5400(0.150)$ \\
${ }^{67} \mathrm{Ga}$ & $1400(0.039)$ \\
${ }^{99} \mathrm{~T} \mathrm{Tc}$ & $520(0.014)$ \\
${ }^{131} \mathrm{I}$ & $520(0.014)$ \\
\hline
\end{tabular}

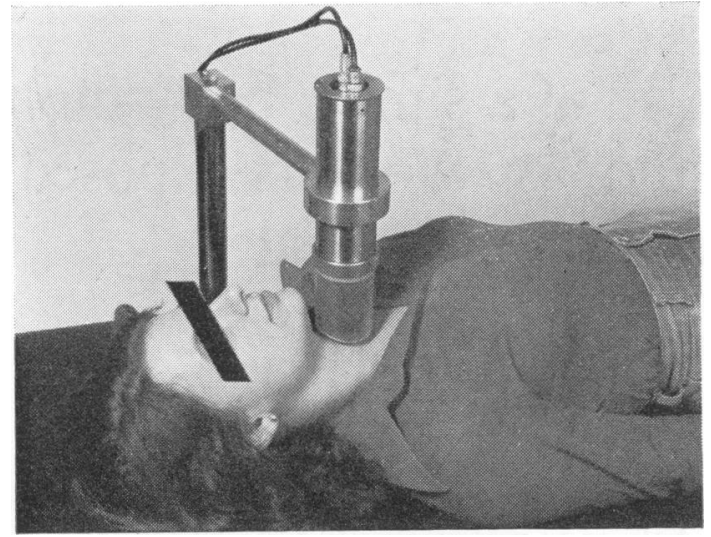

Fig 2 Small NaI detector being used to measure activity in thyroid.

detector are arranged so that the subject's trunk and upper legs lie on a $50-\mathrm{cm}$ arc. In both positions the subject's hands are placed outside the field of view of the detector. Position 1 offers greater sensitivity whereas position 2 gives a response that is less dependent on subject build and activity distribution. The efficiency of the detector has been determined at both positions for activity concentrated in the chest and for activity evenly distributed in the whole body.

Using a 500-second count, the $95 \%$ detection activities for a nuclide with $100 \%$ gamma emission between 0.1 and $3.0 \mathrm{MeV}$ are roughly as follows:

At position 1: $400 \mathrm{~Bq}(0.011 \mu \mathrm{Ci})$ evenly distributed in the whole body

or $190 \mathrm{~Bq}(0.005 \mu \mathrm{Ci})$ concentrated in the chest.

At position $2: 550 \mathrm{~Bq}(0.015 \mu \mathrm{Ci})$ evenly distributed in the whole body

or $340 \mathrm{~Bq}(0.009 \mu \mathrm{Ci})$ concentrated in the chest. The $95 \%$ detection activity is the activity that, if present in a subject, would be detected on $95 \%$ of occasions, given average background and subject build. It corresponds to about $\mathbf{4 . 6}$ standard deviations of the background counting rate. ${ }^{5}$ Table 1 shows $95 \%$ detection activities at position 1 for specific nuclides.

Thyroid measurements are usually performed with the subject lying on an examination couch with the detector positioned directly over the thyroid (fig 2). If significant activity is detected effective thyroid depth can be allowed for by making a second measurement at a more distant position. ${ }^{6}$ At the close position, and for a 500 -second count, the $95 \%$ detection activity is about $30 \mathrm{~Bq}(0.0007 \mu \mathrm{Ci})$ of ${ }^{125} \mathrm{I}$ or $60 \mathrm{~Bq}(0.0015 \mu \mathrm{Ci})$ of ${ }^{131} \mathrm{I}$, assuming an effective thyroid depth of $2 \mathrm{~cm}$ (table 2). 
Table $2 \quad 95 \%$ detection activities for thyroid measurements, for a 500-second count, assuming an effective thyroid depth of $2 \mathrm{~cm}$

\begin{tabular}{ll}
\hline Nuclide & $95 \%$ detection activity $\mathrm{Bq}(\mu \mathrm{Ci})$ \\
\hline${ }^{125} \mathrm{I}$ & $30(0.0007)$ \\
${ }^{131} \mathrm{I}$ & $60(0.0015)$ \\
\hline
\end{tabular}

\section{Results of pilot study}

The Board's equipment has been used at 11 establishments in England where unsealed sources are used. The establishments included hospitals, universities, and the research laboratories of private companies and government organisations. During the pilot study, 109 subjects, who may have been exposed to unsealed gamma-ray emitting material, have been measured, 44 by whole-body counting and 68 by thyroid counting (three by both methods).

The subjects measured were not specially selected as being most likely to have some internal contamination. They included some who handled quantities of unsealed material and some who worked in areas where operations with unsealed material were carried out by others. A few were not normally exposed to unsealed radioactive material but had worked in an area where a leaking radiotherapy source had been discovered. Taken as a group, the subjects measured had possibly been exposed to over 30 different gamma-ray emitting nuclides. The most common were ${ }^{125} \mathrm{I},{ }^{99 \mathrm{~m}} \mathrm{Tc},{ }^{51} \mathrm{Cr},{ }^{131} \mathrm{I}$, and ${ }^{137} \mathrm{Cs}$. Some activity, other than that due to naturally occurring ${ }^{40} \mathrm{~K}$, was detected in 33 cases, $30 \%$ of the total.

For the purpose of summarising the findings, the measured activities have been compared with derived investigation levels (DIL) suitable for use in routine monitoring of people chronically exposed to the nuclide detected. A DIL is the activity that if measured in a subject would be sufficient cause for some further investigation to determine the circum- stances of the intake. Table 3 compares the activity measured with the DIL for each nuclide detected during the survey and gives the total number of workers measured who were occupationally exposed to that nuclide. The method by which the DILs were calculated is given later.

In some cases the contamination detected was probably due to a very recent and unusual intake, and therefore a less restrictive DIL would have been more appropriate. In other cases the contamination may have been the result of an old and initially more serious intake, and a more restrictive DIL should have been used. Since the exact time and circumstances of most of the intakes were not known, it was not possible to calculate an individual DIL appropriate to each case. Therefore the DIL for routine monitoring of chronic exposure has been used in all cases as a compromise.

In most cases either activity was not detected or the levels observed were small compared with the appropriate DIL. In view of the small amounts detected and the unknown circumstances of intake calculation of the committed dose equivalents would not normally be appropriate. In a few cases some additional information was available-for example, one case of contamination with 125iodine had previously been recognised, and one case of contamination with ${ }^{131}$ iodine had almost certainly occurred on the day of measurement. In these cases it was possible to provide estimates of the committed dose equivalents.

In view of the foregoing it would be wrong to draw too firm conclusions from the results given. The following three points should, however, be noted.

(1) With simple monitoring equipment, some internal contamination was detected in a sizeable proportion $(30 \%)$ of those subjects measured. In most of these cases only traces of activity were found, which would lead to very small doses.

(2) In a few cases the contamination was significant enough to merit at least some informal investi-

Table 3 Comparison of measured activities, $q$, and derived investigation levels for the contaminating nuclides

\begin{tabular}{|c|c|c|c|c|c|}
\hline \multirow[t]{2}{*}{ Nuclide } & \multirow[t]{2}{*}{$\begin{array}{l}\text { Derived investigation level } \\
\mathrm{Bq}(\mu \mathrm{Ci})\end{array}$} & \multirow[t]{2}{*}{$\begin{array}{l}\text { No of cases possibly exposed to } \\
\text { the nuclide }\end{array}$} & \multicolumn{3}{|c|}{$\begin{array}{l}\text { No of cases in which some activity, } q \text {, } \\
\text { was detected }\end{array}$} \\
\hline & & & $q<\frac{1}{\text { to }} D I L$ & to $D I L<q<D I L$ & $q>D I L$ \\
\hline${ }^{125} I$ & $9 \times 10^{3}(0.2) \mathrm{T}$ & 66 & 18 & 2 & 1 \\
\hline${ }^{31} I$ & $2 \times 10^{3}(0.05) \mathrm{T}$ & 10 & & 1 & $2^{*}$ \\
\hline${ }^{99 \mathrm{~m}} \mathrm{Tc}$ & $1 \times 10^{6}(30) \mathrm{WB}$ & 10 & $7^{*}$ & & \\
\hline${ }^{67} \mathrm{Ga}$ & $3 \times 10^{5}(8)$ WB & 10 & & $1^{*}$ & \\
\hline${ }^{137} \mathrm{Cs}$ & $2 \times 10^{5}(6) \mathrm{WB}$ & 7 & 2 & & \\
\hline
\end{tabular}

$T=$ In thyroid. WB $=$ In whole body.

${ }^{*}$ Two cases of multiple contamination, one with ${ }^{131} \mathrm{I}$ and ${ }^{99 \mathrm{~m}} \mathrm{Tc}$ and one with ${ }^{67} \mathrm{Ga}$ and ${ }^{99 \mathrm{~m}} \mathrm{Tc}$. 
gation as to how it had occurred. In most such cases it was possible to trace the intake to a particular incident in which equipment had failed to operate properly or staff had not followed the usual safety precautions.

(3) Radioisotopes of iodine present a particular problem because of volatility and because relatively large quantities are sometimes handled.

\section{Investigation levels}

When a programme of monitoring is undertaken it is useful to have a predetermined investigation level (IL). The International Commission on Radiological Protection has suggested 7 that for routine monitoring it is most appropriate to base the IL on the fraction of three-tenths of the dose equivalent limit, corresponding to the fraction of the year to which the individual monitoring measurement refers. Corresponding DILs can then be deduced for the quantities directly measured. The results of the measurements can be compared with the DIL to decide whether any investigation to determine the circumstances of an intake is necessary.

The DILs used in table 3 were obtained as follows. A sampling interval-T, suitable for routine monitoring of people chronically exposed to each nuclide, was chosen. $T$ must be such that reasonable assessments of committed dose equivalent from any intakes during the period can be made from the measurement results. Therefore, a value of $T$ has been chosen that is close to the effective half-life for the nuclide. The ILs were then calculated from:

$$
\mathrm{IL}=0.3 \times \mathrm{ALI} \times \frac{\mathrm{T}}{365}(\mathrm{~T} \text { in days })
$$

where the ALI is the annual limit of intake for the nuclide in question. The ALI for inhalation of a readily transportable compound (lung class $D$ ) was used in all cases. Finally, the DIL was found by calculating the retained fraction of uptake at the time of sampling that would result from an intake of one IL mid-way through the sampling period.
Table 4 gives the ALIs, the sampling interval chosen, and the resulting ILs and DILs for some commonly used nuclides. (Values of ALIs and all metabolic data were taken from Adams et al. ${ }^{8}$ )

\section{Need for monitoring}

This study has confirmed that people occupationally exposed to unsealed radioactive material do acquire low levels of internal contamination from their work. Investigators in the USA have also noted this. ${ }^{2} 910$ Although it is usual for work with radioactive materials to be carefully controlled and supervised, significant intakes do occasionally occur especially where the quantities of activity handled are large. Monitoring of the working environment must be the primary method of assessing the hazard to worke1s or the effectiveness of safety procedures for the containment of radioactive material, but monitoring of the environment cannot detect all circumstances in which a significant intake may have occurred. Therefore some form of personal monitoring for internal contamination, bioassay, or body measurement should be carried out whenever workers might acquire significant internal contamination.

The ICRP has recommended? that workers whose annual exposure might exceed three-tenths of the dose equivalent limit should be the subject of individual monitoring for external radiation or internal contamination and dose or intake recordings as appropriate. In the case of exposure to unsealed radioactive material, control of internal exposure can be based on ALIs. Thus workers occupationally exposed to unsealed radioactive material should be the subject of personal monitoring and dose or intake recording where annual intake might exceed three-tenths of the ALI.

\section{Monitoring programmes}

Any programme of monitoring should be designed to fulfil a need and be appropriate to the level and type of exposure. In practice body monitoring will be

Table 4 Annual limits of intake, possible sampling periods for routine monitoring and subsequent investigation levels and derived investigation levels for some commonly used nuclides

\begin{tabular}{llcll}
\hline Nuclide & $\begin{array}{l}\text { ALI for inhalation } \\
(\text { class } D), B q\end{array}$ & $\begin{array}{l}\text { Sampling period, } \\
\text { days }\end{array}$ & Investigation level, Bq & Derived investigation level, Bq ( $\mu$ Ci) \\
\hline${ }^{51} \mathrm{Cr}$ & $2 \times 10^{9}$ & 14 & $2 \times 10^{7}$ & $5 \times 10^{6}(140) \mathrm{WB}$ \\
${ }^{67} \mathrm{Ga}$ & $6 \times 10^{8}$ & 3 & $1 \times 10^{6}$ & $3 \times 10^{5}(8) \mathrm{WB}$ \\
${ }^{90 \mathrm{~m} T c}$ & $1 \times 10^{10}$ & 1 & $8 \times 10^{6}$ & $1 \times 10^{6}(30) \mathrm{WB}$ \\
${ }^{125} \mathrm{I}$ & $2 \times 10^{8}$ & 42 & $7 \times 10^{4}$ & $9 \times 10^{3}(0 \cdot 2) \mathrm{T}$ \\
${ }^{131}$ & $2 \times 10^{6}$ & 8 & $1 \times 10^{4}$ & $2 \times 10^{3}(0 \cdot 05) \mathrm{T}$ \\
${ }^{137} \mathrm{Cs}$ & $6 \times 10^{6}$ & 110 & $5 \times 10^{5}$ & $2 \times 10^{5}(6) \mathrm{WB}$ \\
\hline
\end{tabular}

$T=$ In thyroid. WB $=$ In whole body. 
most acceptable if it introduces a minimum of inconvenience. The measurements are therefore best made at the place of work. Two possibilities exist: either the monitoring equipment can be permanently available at the place of work, or a mobile system, operated by some central agency, could be used to visit any establishments where monitoring is required. The first possibility may be appropriate to major establishments where there are a considerable number of people working regularly with unsealed gamma sources. For smaller users, however, where large activities are used only infrequently, the first possibility may not be economically viable. Even establishments that possess the necessary equipment and expertise may prefer some measurements to be made by an operationally independent organisation such as the Board.

Routine monitoring-Where there are continuing potential exposures to high activities ICRP suggests that routine monitoring will be appropriate. The interval between measurements should be frequent enough to allow meaningful estimates of initial intake or committed dose equivalent to be made from the results of the measurements. This will entail monitoring at intervals comparable to the effective half-life of the nuclides concerned. If nuclides with short effective half-lives (less than about two weeks) are used the establishment concerned should itself have the resources to carry out any necessary routine monitoring. Most commonly used gamma-ray emitting nuclides can be detected easily at the required levels using even simpler equipment than that described here. ${ }^{4}{ }^{125}$ I is one of the most common unsealed sources in use, and rough estimates of thyroid content of this nuclide can be made with hand-held monitoring equipment provided the correct calibration procedures are carried out. When routine monitoring is performed by bioassay or simple body measurements, occasional checks with more sophisticated monitoring equipment might be useful.

Operational monitoring - When potential exposure arises from a particular process or operation that may be carried out only infrequently, ICRP suggests that operational monitoring is appropriate-that is, monitoring to assess the initial intake or committed dose equivalent arising from the particular operation. In this case monitoring should preferably be performed shortly after the operation. In any case the measurement must be made at such a time that the retained fraction of any significant initial intake would still be easily measurable. Again it would be desirable for the establishment concerned to be able to perform some form of monitoring, but if the dates on which operations that may lead to a significant intake are known, and the nuclide concerned has a reasonably long effective half-life so that doses and intakes from a particular operation may be reliably assessed some time afterwards, monitoring by an outside agency may be adequate.

Special monitoring-Where there have been some abnormal circumstances that may have led to exposure, ICRP recommends that special monitoring be carried out. This should be done as soon as possible after the discovery that there may have been exposure. In this case adequate monitoring equipment may not be available at the place of work, and monitoring by another organisation like the NRPB would seem desirable.

Finally, for workers for whom the probability of any significant intake is low, so that monitoring procedures as above are not thought essential, occasional monitoring may be carried out to reassure staff and safety advisers that the safeguards employed are effective.

I thank the radiation safety advisers and staff of the establishments visited during the pilot survey for their co-operation and hospitality.

\section{References}

1 Vennart $\mathrm{J}$. Whole body counters in routine monitoring. Health Phys 1967;13:61-72.

2 Masse FX, Bolton MM. Experience with a low cost chair type detector system for the determination of radionuclide body burdens of MIT radiation workers. Health Phys 1970;19:27-35.

${ }^{3}$ Mizushita S. Portable chair type whole body counter. J Nucl Sci Technol 1977;14:911-5.

4 Palmer HE, Branson BM, Cohn SH, et al. Standard field methods for determining ${ }^{137} \mathrm{Cs}$ and ${ }^{131} \mathrm{I}$ in vivo. Health Phys 1976;30:113-8.

${ }^{5}$ Currie LA. Limits for qualitative detection and quantitative determination. Anal Chem 1968;40:586-93.

- Schulz AG, Rollo FD. A method for measuring radioiodine uptake which corrects for thyroid depth. $J$ Nucl Med 1970;11:508-13.

7 International Commission on Radiation Protection. Recommendations of the International Commission on Radiological Protection. Oxford: Pergamon Press, 1977. (Publication 26.)

${ }^{8}$ Adams N, Hunt BW, Reissland JA. Annual limits of intake of radionuclides for workers. Harwell: National Radiological Protection Board, 1978. (NRPB-R82.)

- Athey JW, Killian G, Duggan MA, et al. Whole body counting of some radioactive isotopes and radiopharmaceutical production workers. Am Ind Hyg Assoc 1970; $31: 707-11$.

${ }^{10}$ Shlien B, LeCroy E. Results of thyroid and whole-body counting of some medical and paramedical personnel. J Nucl Med 1971;12:523-5. 